\title{
Plano de classificação de documentos arquivísticos e a teoria da classificação: uma interlocução entre domínios do conhecimento
}

Elaine Rosa Rios

Analista de Documentação da Agência Nacional do Petróleo, Gás Natural e dos Biocombustíveis. Mestre em História Social pela UFRJ. Especialista em Planejamento, Organização e Direção de Arquivos (UFF/Arquivo Nacional)

Rosa Inês de Novais Cordeiro
Professora do Departamento de Ciência da Informação e do Programa de Pós-Graduação em Ciência da Informação da UFF. Doutora em Comunicação e Cultura (UFRJ).Mestre em Comunicacão (UFRJ)

Estudo sobre os princípios teóricos e metodológicos que envolvem a elaboração dos planos de classificação documental em arquivos, com ênfase no conhecimento do contexto, no qual se insere a instituição. Os princípios da teoria da classificação que regem a construção de linguagens documentárias e, em especial, as notacionais, no âmbito da organização do conhecimento, devem fundamentar a construção dos planos de classificação para documentos arquivísticos. Conclui que a Arquivologia deve aprofundar o diálogo com outras áreas do conhecimento, especialmente a Ciência da Informação, no que tange à análise e a representação do conhecimento.

Palavras-chave: Planos de Classificação de Documentos em Arquivos; Linguagens Documentárias Notacionais; Teoria da Classificação.

\section{Document Classification Plans in Archives and Classification Theory: a dialogue among knowledge domains}

This study presents and discusses the theoretical and methodological principles that guide the elaboration of 
document classification plans in archives. The emphasis is on the knowledge of the institutional framework. The principles of classification theory pertaining the construction of documentary languages and specially, classification schemes in the scope of the organization of knowledge must be taken into consideration in document classification plans in archives. Finally, it is concluded that for elaboration of such plans, interaction between several areas of knowledge, specifically between Archivology and Information Science should occur regarding analysis and document representation.

Keywords: Archive Documents Classification Plans; Documentary Languages Notations; Classification Theory.

Recebido em 24.08.2009 Aceito em 30.06.2010

\section{Introdução}

Esta pesquisa tem como objeto de estudo a análise de alguns princípios que são aplicados aos planos de classificação de documentos arquivísticos, relatados na literatura arquivística ou presentes nos sites de arquivos e, que serão vistos a partir da teoria analítico-sintética, ou seja, da teoria da classificação facetada que tem sido um referencial marcante para as discussões da organização do conhecimento ${ }^{1}$. Para isto consideraremos, de forma acentuada, determinados fundamentos da teoria da classificação facetada que sustentam as discussões no âmbito da Organização do Conhecimento e, em particular, sobre as linguagens documentárias notacionais nos estudos da representação ou da análise documentária ${ }^{2}$. É uma pesquisa de natureza bibliográfica e que não tem como intenção a realização de estudo empírico.

Diante disso, tentaremos praticar a interlocução entre as áreas da Ciência da Informação, da Biblioteconomia e da Arquivística. Nesta última, a instância de domínio é da Gestão de Documentos ${ }^{3}$, no que tange aos seus instrumentos de gestão, tais como: o Plano de Classificação de Documentos Arquivísticos, a Tabela de Temporalidade Documental e o Manual de Gestão Arquivística de Documentos. Enfocaremos aqui o primeiro instrumento citado.

\footnotetext{
${ }^{1}$ Neste artigo usaremos a expressão "Organização do Conhecimento" para abrigar também os termos organização da informação e organização dos documentos. Para discussão sobre essa temática Cf. Brascher; Café (2008).

${ }^{2}$ Sobre esse tema destacamos, entre outros, os seguintes autores seminais: Ranganathan (1967);

Foskett (1973); Vickery (1980).

${ }^{3}$ A Lei Federal n. 8159/91, suporte legal que regula a Política Nacional de Arquivos Públicos Federais, define a Gestão de Documentos como o conjunto de procedimentos e operações técnicas referentes à produção, tramitação, uso, avaliação e arquivamento de documentos em fase corrente e intermediária, visando a sua eliminação ou recolhimento para guarda permanente.
} 
Cabe recordar que no século XIX, o livre acesso aos livros (livre acesso às estantes) nas bibliotecas impulsionou os procedimentos classificatórios que possibilitaram a organização dos livros por assuntos e não mais por sistemas filosóficos ou práticos, permitindo o entendimento do usuário pela organização dos livros adotada pelas bibliotecas, uma vez que, a demanda e o interesse do usuário encontravam-se nos assuntos que podiam ser localizados nos livros, e constituíram a base de sistematização dos primeiros sistemas de classificação nas bibliotecas. Portanto, nas palavras de Barbosa (1969, p. 13): "E, assim, sugiram os grandes sistemas de classificação, muitos dos quais, como os decimais, com algumas modificações, são hoje usados nas bibliotecas [...]", como por exemplo, a Classificação Decimal de Dewey que é considerado um sistema de classificação enumerativo.

Temos aqui, então, a idéia e a prática já circulantes na sociedade do século XIX quanto ao acesso e ao uso de documentos. Esta idéia também chega aos arquivos e, em consequência, à literatura arquivística ${ }^{4}$, mas em uma linha de tempo diferente da biblioteconômica ${ }^{5}$.

A crescente preocupação dos arquivos públicos em perpetuar a memória coletiva social, através da preservação dos seus acervos documentais para posterior acesso, os levou a adotar como prática e recurso sistematizador a elaboração de instrumentos de pesquisa ${ }^{6}$, a fim de permitir que os mesmos fossem facilitadores e mediadores de informações sobre 0 conjunto documental, além de fornecerem informações sobre pontos de acesso aos documentos, ou seja, o uso dos instrumentos de pesquisa para o acesso aos documentos.

\section{Propostas teórico-metodológicas}

No contexto arquivístico, a elaboração e o emprego de planos de classificação estão situados na fase corrente dos documentos, de modo a auxiliar na racionalização dos procedimentos para a gestão documental institucional e, por fim, integrarem a política de informação em arquivos, seja esta de natureza pública ou privada.

O plano de classificação de documentos é nomeado também na literatura da área como Código de Classificação de Documentos de Arquivo, entre outras denominações ${ }^{7}$. À luz dos verbetes dicionarizados nas fontes abaixo, ele é assim definido:

\footnotetext{
${ }^{4}$ Sobre a questão do acesso à informação nos arquivos, destacamos como importante fonte de pesquisa a tese de doutorado de Fernanda Ribeiro (1998), que analisa o tema em uma perspectiva histórica e no cenário internacional, para depois contextualizar os arquivos de Portugal.

5 Para a abordagem deste tema, ver Ribeiro (1998).

${ }^{6}$ Ribeiro (1998) usa a expressão "instrumentos de acesso" à informação, que consideramos termo com precisão terminológica relevante. Ainda, em Portugal e nos países lusófonos africanos denominam meios de busca conforme Bellotto (2004, p. 180). Esta autora também descreve que a expressão instrumento de pesquisa vem do francês instruments de recherche, mas os franceses também usam instruments de descripción. Na Espanha emprega-se instrumentos de descripción e na Inglaterra finding aids.

7"Alguns autores o chamam de quadro de classificação ou quadro de arranjo, outros de código de classificação, de plano de classificação, de plano de arranjo, de esquema de classificação, de
} 
Esquema de distribuição de documentos em classes, de acordo com métodos de arquivamento específicos, elaborados a partir do estudo das estruturas e funções de uma instituição e da análise do arquivo por ela produzido. Expressão geralmente adotada em arquivos correntes (ARQUIVO NACIONAL, 2005, p. 132).

Esquema pelo qual se processa a classificação de um arquivo (CAMARGO; BELLOTTO, 1996, p. 60).

Como mencionado, o plano de classificação de documentos de arquivos é desenvolvido para ser aplicado já na fase corrente dos documentos de arquivos, sendo, portanto, um "instrumento de trabalho usado para classificar todo e qualquer documento produzido ou recebido por um órgão no exercício de suas funções e atividades". Seu objetivo é agrupar documentos sobre um mesmo assunto, representado por uma notação (codificação) e, também, implica na organização física dos documentos arquivados para a sua busca (recuperação) notacional.

A expressão assunto ou tema deve ser analisada considerando-se o conteúdo do documento, logo, uma ideia (conceito) será denotada por termos ou notações. Nos planos de classificação, teremos as notações e as descrições dos assuntos correspondentes; já nas listas de cabeçalhos de assunto, tesauros e vocabulários controlados encontraremos os termos autorizados para o uso no sistema arquivístico.

No entanto, a ideia de assunto ${ }^{8}$ deverá ser vista de modo lato, pois nos Planos de Classificação de Documentos de Arquivos, os assuntos estão presentes nas diversas classes e subclasses do esquema - a disposição hierárquica das classes pela divisão em cadeia ${ }^{9}$ reflete a estrutura, as funções e as atividades da instituição. O assunto poderá ser uma disciplina, ramo ou tópico do conhecimento, espaço geográfico, época, período ou tempo cronológico, pessoa ou instituição e, de maneira secundária, um assunto poderá ser completado com a indicação de uma forma intelectual, de apresentação e física.

Baseada na ideia de assunto, na teoria da classificação facetada podemos entender que a declaração de assunto ${ }^{10}$ de um documento poderá ser a manifestação, pelo menos, de uma das facetas: coisa/produto (ou de parte da coisa/parte do produto) ação (processo/operação/atividade), material, agente/instrumento, propriedades, lugar, tempo e forma.

tabela de classificação. Qual denominação devemos utilizar? [...] esquema e plano são as duas palavras que melhor revelam a idéia de um instrumento de classificação" (SOUSA, 2007, p.8687).

${ }^{8}$ Cf Hjorland (1992).

${ }^{9}$ Subdivisões descendentes e sucessivas, que se movem de um assunto geral para um assunto específico. Cf. Piedade, 1983, p. 27.

${ }^{10}$ Frase-síntese declarada pelo indexador, ainda em linguagem natural, que indica o(s) assunto(s) tratado(s) no documento. 
Então, essas facetas podem também ser usadas para a estruturação das classificações bibliográficas, tesauros, ontologias e demais instrumentos que visam à organização do conhecimento em ambientes não eletrônicos ou eletrônicos. Em uma suposição teórica, podemos concluir que os planos de classificação de documentos arquivísticos organizados pela estrutura funcional deverão refletir, de forma intensa, assuntos resultantes da faceta Ação.

Ponderando que determinado documento será melhor representado pela junção de assuntos principais e assuntos complementares, os sistemas de classificação bibliográficos $\left(\mathrm{CDD}^{11}{ }^{11} \mathrm{CDU} \mathrm{U}^{12}\right.$, entre outros) têm como um dos seus princípios a possibilidade da interlocução entre os temas. Na CDD, acontece na relação entre as classes e as subclasses com as tabelas auxiliares. Na CDU, a relação é entre classes e subclasses das diferentes hierarquias, e destas com as tabelas analíticas especiais e tabelas auxiliares comuns.

Diante disso, a ordem de citação dos assuntos (ordem de combinação dos assuntos ou ordem da sequência seguida na notação ao se classificar) determinará a chave de entrada da notação, isto é, a ordem de combinação dos temas/assuntos por suas notações; que assuntos serão principais (virão em primeiro lugar/classificação principal) e que assuntos serão complementares e secundários (virão em segundo lugar/classificações secundárias). Por exemplo: Administração da qualidade ambiental (notação $x$ ) das indústrias químicas (notação y) de São Paulo (notação $z$ ), na década 90 (notação $\beta$ ). Portanto, como ficará a ordem de citação (ordem de combinação) deste assunto que será representado pelas suas respectivas notações? Quais os tipos de relacionamentos entre as notações dos assuntos? Esta relação ou combinação entre os assuntos, ou seja, entre os conceitos, é um dos princípios fundamentais da teoria da classificação, quando aplicamos o princípio de faceta ${ }^{13}$ na construção de esquemas de classificação ou na descrição de assuntos, o que resulta, então, no que denominamos de relacionamento entre os assuntos/entre as classes. Não observamos nos planos de classificação de documentos arquivísticos a aplicação deste critério.

Os sistemas modernos, os ditos sistemas em facetas [tentam incluir a idéia de faceta], são elaborados a base de conceitos simples e dão grande importância aos relacionamentos, atribuindo ao ato de classificar a tarefa de construir os símbolos de classificação pelo relacionamento de conceitos originários de diversas facetas (PIEDADE, 1983, p. 30).

\footnotetext{
${ }^{11}$ Classificação Decimal de Dewey.

${ }^{12}$ Classificação Decimal Universal.

${ }^{13} \mathrm{O}$ sistema de Classificação de Dois Pontos é totalmente facetado, mas a CDD e a CDU procuram considerar o princípio da faceta, embora não os levem às ultimas consequências.
} 
O primeiro passo teórico-metodológico a ser dado na elaboração do plano de classificação de documentos arquivísticos ${ }^{14}$ é delimitar conceitualmente 0 sujeito criador da documentação arquivística. Respostas para questões práticas, como delimitar o fundo arquivístico, podem ser buscadas nos trabalhos clássicos de Duchein (1982-1986).

A seguir, dois possíveis critérios poderão ser adotados nos planos de classificação para sua elaboração: o funcional e o estrutural. O primeiro corresponde às funções ${ }^{15}$ de uma entidade coletiva, sendo o procedimento tradicionalmente mais usado nos arquivos. O segundo refere-se às divisões, aos setores e aos departamentos de uma instituição e, apesar de ser menos usado, alguns profissionais da área ${ }^{16}$ consideram que talvez possa refletir melhor alguns aspectos das exigências da classificação arquivística. Esses critérios serão discutidos na sequência deste artigo.

\subsection{A escolha de uma base de divisão}

$\mathrm{Na}$ elaboração dos planos de classificação de documentos arquivísticos, autores como Sousa (2007) e Héon (1995) entendem que o princípio da proveniência em seus dois níveis de desdobramento, o respeito aos fundos e a ordem original, é a base de todo trabalho de classificação em arquivos, por trazer em seu bojo a necessidade de conhecimento do sujeito criador do arquivo, quer seja pessoa física ou jurídica. Garon (1992 apud HÉON, 1995) e Héon (1995) nos auxiliam a entender claramente este enunciado, pois para o primeiro, a elaboração de um plano de classificação adequado exige que se tenha uma "visão do conjunto dos documentos a classificar" e para tanto, o primeiro passo a ser dado é fixar os limites externos do conjunto, o que só é possível, conceitualmente, através da aplicação do princípio de respeito aos fundos ou proveniência. Héon é enfático neste ponto, ao afirmar que o "[...] o plano de classificação fornece a prova tangível da aplicação do princípio de respeito aos fundos de arquivos." (HÉON, 1995, p. 77, tradução nossa).

A importante posição conceitual de Garon (1969 apud HÉON, 1995) sobre a possibilidade de se partir do princípio da proveniência para a elaboração de um plano de classificação de documentos arquivísticos foi retomada, segundo Héon (1995), nos anos de 1974-1975, por dois autores canadenses, Freniére e Renaud, sendo que o primeiro propôs uma maneira de operacionalizar o sistema de classificação, distinguindo-se duas categorias de funções desempenhadas pelas empresas, a saber: uma, ligada às atividades-meio, comuns à maioria das empresas, e a outra seria atinente às atividades-fim, específicas de cada organização. Por sua vez, cada categoria apresentaria divisões segundo as quais seriam

\footnotetext{
${ }^{14}$ Como é sabido, a classificação do conhecimento é a origem da sistematização e estruturação dos esquemas de classificações bibliográficas.

${ }^{15}$ As funções de entidades coletivas associadas à produção e manutenção de arquivos devem ser analisadas em observância à Norma Internacional para Descrição de Funções do Conselho Internacional de Arquivos (2008).

${ }^{16}$ Cf. Oliveira (2001).
} 
distinguidas, de maneira hierárquica, as funções (classes), as subfunções (subclasses), as atividades (divisões) e subatividades (divisões de nível inferior). Se necessário, poder-se-ia ainda introduzir três tipo de subdivisões: a subdivisão uniforme, de acordo com a natureza dos documentos; a subdivisão específica e a subdivisão nominativa. No manual de classificação de documentos administrativos da Universidade Laval do Canadá (2009), podemos observar, na prática, a aplicação desse princípio de divisão, baseado nas funções de uma instituição e preconizado por Roberge (1985).

Aqui é recomendável a inclusão dos conceitos de função e atividade, que estão contemplados na Norma Internacional para a Descrição de Funções (ISDF) em sistemas arquivísticos do Conselho Internacional de Arquivos (CIA, 2008).

Então, função é entendida como:

Qualquer objetivo de alto nível, responsabilidade ou tarefa prescrita como atribuição de uma entidade coletiva pela legislação, política ou mandato. Funções podem ser decompostas em conjuntos de operações coordenadas, tais como subfunções, procedimentos operacionais, atividades, tarefas ou transações (CIA, 2008, p.13).

Por consequência, atividade é:

Tarefa desempenhada por uma entidade coletiva para realizar cada uma das suas funções. Pode haver várias atividades associadas a cada função. Em certos casos, algumas atividades podem ocorrer sob diferentes funções. Atividades abraçam transações que, por seu turno, produzem documentos. São exemplos (para a função de recrutamento) seleção, lotação, monitoramento e avaliação.

O módulo 4 do curso sobre gestão de documentos ativos do Portail International Archivistique Francophone (PIAF) sintetiza bem a questão da escolha de uma base de divisão para a elaboração de um plano de classificação de documentos arquivísticos, encarando-a como uma etapa fundamental da estruturação das classes. O problema residiria em se recorrer às diversas bases de divisão para uma mesma estrutura de classificação, pois as classes podem ser baseadas nas grandes atividades; nos tipos de documentos e nos tipos de organização. Indo um pouco mais longe, o módulo chama atenção para o fato de que diversas bases podem ser usadas; por outro lado, outras devem ser evitadas, especialmente as divisões por: a) tipo de documento (por possuir pouco significado); e b) estrutura ou organograma do órgão (por sofrer modificações ao longo do tempo). 
Preocupado com essa questão dos níveis de divisão na elaboração dos planos de classificação, pois os mesmos formarão os conjuntos de acordo com as divisões realizadas no fundo, Sousa (2007) observa que o primeiro nível de divisão está vinculado, direta ou indiretamente, à missão do produtor. As funções, por sua vez, determinariam o segundo nível de divisão. Entretanto, nas demais divisões surgem diferentes princípios de divisão, como atividades, tipologia documental etc., o que não é recomendado em termos de classificação, como foi demonstrado anteriormente.

Do que foi exposto, temos, assim, o princípio de respeito aos fundos como primeiro recorte conceitual a ser realizado no objeto a classificar. Entretanto, é na filosofia, como ressalta Pombo (1998), que encontramos o embasamento teórico para as relações hierárquicas que são estabelecidas na estruturação dos planos. Porém, a teoria da classificação incorpora em seus princípios as discussões sobre as relações hierárquicas advindas da filosofia, da lógica aristotélica, que podem ser aplicadas às áreas do saber, a exemplo de se utilizar um único princípio de divisão, o princípio da divisão em cadeia $^{17}$, orientação esta que foi igualmente encontrada na literatura arquivística que trata da construção dos planos de classificação.

A despeito de toda a discussão que envolve a escolha de um princípio de divisão, após a estruturação das classes, torna-se necessária a adoção de um método para indicar esta ordem e as combinações estabelecidas e isto é instrumentalizado pelo código ou notação, o qual é comumente denominado na literatura arquivística como codificação.

Conforme Barbosa (1969, p. 33):

A notação de um sistema de classificação é [...] o conjunto de símbolos que representa o assunto ou os assuntos dos livros [documentos]. É imprescindível a qualquer sistema por ser a representação simbólica dos assuntos.

Completando a citação acima, recorremos a Piedade (1983, p. 38) que define a notação como:

[...] o conjunto de símbolos destinados a representar os termos da classificação, traduzindo em linguagem codificada o assunto dos documentos, e permitindo sua localização nas estantes, nos catálogos e nas tabelas de classificação.

Os caracteres empregados na notação tanto podem ser números, letras e sinais gráficos e, quando se emprega apenas um caractere, é chamada notação pura. Ao contrário de quando se empregam vários tipos de caracteres, estes recebem a denominação de notação mista. Sua principal função é a de localizar os assuntos no acervo, mas também

\footnotetext{
${ }^{17}$ Subdivisões descendentes e sucessivas, que se movem de um assunto geral (classe geral) para um assunto específico (subclasse). Cf. Piedade, 1983, p. 27.
} 
possibilita a ordenação lógica e física, dos próprios documentos, pelos seus respectivos assuntos. Piedade (1983, p. 40-41) resume as finalidades e as qualidades que a mesma deve apresentar e, dentre elas, destacamos: a capacidade de traduzir em símbolo 0 assunto dos documentos; permitir a sua ordenação lógica, segundo os assuntos de que tratam; possibilitar a sua síntese; mostrar a hierarquia ou a estrutura do sistema de classificação; indicar a ordem dos assuntos de modo exato e imediato, a fim de permitir a localização da informação procurada; possibilitar revelar integralmente 0 assunto do documento (especificidade); ser hospitaleira, isto é, permitir o número de subdivisões necessárias a cada assunto; ser flexível ou expansiva, isto é, permitir a inclusão de novos assuntos nas posições mais convenientes; revelar a estrutura da classificatória, a sua hierarquia, isto é, mostrar as classes relacionadas e as classes subordinadas (expressividade).

O que a primeira vista seria apenas a escolha de um caractere, um conjunto de símbolos, o que nós temos, no entanto, é toda a complexidade que envolve o processo classificatório sintetizado na notação, pois ela traz no seu âmago as principais questões teóricas e metodológicas que se encontram subjacentes na elaboração de planos de classificação. Daí, uma de suas funções é permitir a síntese, ou seja, formar símbolos que representem os assuntos compostos ou complexos.

Entretanto, apesar de sua importância na construção dos planos de classificação, só encontramos uma preocupação analítica com relação à notação na literatura arquivística pesquisada, no módulo 4 do curso de Gestão e Tratamento do PIAF (2008).

Elementos relativos à qualidade da notação, como simplicidade, flexibilidade, seu caráter sintético e revelador da estrutura do plano de classificação são encontradas nas duas abordagens. O diferencial repousa na própria essência do documento arquivístico: sua organicidade.

[...] a notação facilita a reconstituição dos dossiês, sobretudo aqueles que são compostos de documentos de formas variadas ou registrados sobre diversos suportes de informação. Como o mesmo código deve ser utilizado por documentos que se reportam ao mesmo assunto, mas conservados em diferentes suportes [...] é é mais fácil recuperar os componentes de um dossiê (PIAF, 2008, p. 9, tradução nossa).

Outro ponto destacado pelo PIAF, com relação à notação, resume bem as principais questões teórico-metodológicas nas quais a construção desse tipo de linguagem documentária está envolvida: a capacidade de adaptação que a classificação deve apresentar frente às realidades administrativas, marcadas por constantes mudanças organizacionais. Nesse sentido, cabe à notação possibilitar a inclusão ou a exclusão de subdivisões para refletir a organicidade e a unidade do produtor do arquivo. 


\section{Etapas para a elaboração do plano: possíveis caminhos a percorrer}

Acreditamos que uma preocupação recorrente nos estudos arquivísticos - e isto se reflete nas graduações de Arquivologia ${ }^{18}$ - é a elaboração de linguagens documentárias notacionais (planos de classificação de documentos) ou verbais (listas de cabeçalhos de assunto e tesauros), fundamentada em princípios da teoria da classificação, que está no âmbito da análise e representação documentária ${ }^{19}$, somando-se a isto os conhecimentos da arquivística e suas demais áreas de interlocução. A proposta de construção de instrumentos de representação da informação com bases intuitivas e ad hoc, além do escasso conhecimento sobre a produção dos documentos, é inviável, tendo em vista o atual estágio de desenvolvimento acadêmico da área. A construção dessas linguagens documentárias é uma atividade de compartilhamento de conhecimentos, com o envolvimento de expertises de diversos profissionais em diferentes momentos da atividade. Ressaltamos a importância do diálogo entre o conhecimento teórico e tácito, como, a seguir, procuramos descrever de forma exploratória.

Para a elaboração do plano, é necessário o conhecimento do ambiente organizacional e seus conceitos, o que não significa uma descrição de suas atribuições e funções, mas antes de tudo, uma investigação da organização no seu contexto histórico, como parte da sociedade. Em Sousa (2007), os procedimentos metodológicos partiriam da identificação e compreensão do criador/produtor (organização, entidade, instituição) e de seus produtos (documentos arquivísticos).

A partir das três atividades assinaladas por Belloto (2004) para a organização dos documentos de um fundo de arquivo, Sousa (2007) entende que é possível encontrar também as informações necessárias para a elaboração dos planos de classificação documental, quais sejam: levantamento da evolução institucional da organização, a partir de sua dimensão histórica, levantamento da organização em sua individualidade, ou seja, sua missão, estrutura, funções, atividades e procedimentos formais e informais, e levantamento dos documentos acumulados (produzidos/recebidos) - condições de produção e acumulação e criação de tipologias documentais.

\footnotetext{
${ }^{18}$ No curso de graduação em Arquivologia da Universidade Federal Fluminense são ministradas disciplinas, há mais de quinze anos, cujos conteúdos abarcam a teoria da classificação e demais temas da organização do conhecimento e da informação.

${ }^{19}$ Esta especialidade tem dialogado com outras áreas do conhecimento. Por exemplo, os estudos terminológicos. Cf. Lara (2004).
} 
Por outro lado, em uma perspectiva de análise empírica, Bernardes (2008) desenvolveu um trabalho com a finalidade de fornecer embasamento técnico e legal para a elaboração de planos de classificação e tabelas de temporalidade, no âmbito da administração pública do Estado de São Paulo.

A despeito do maior ou menor detalhamento das etapas a serem seguidas na elaboração dos planos de classificação de documentos arquivísticos, bem como das características e do público a que cada um se destina, tanto no trabalho de Sousa (2007) de cunho acadêmico, quanto no trabalho de Bernardes (2008) de natureza empírica, encontramos como primeiro recorte do objeto a classificar 0 conhecimento do órgão/entidade produtor de arquivo e seus conseqüentes desdobramentos, a saber: o levantamento de sua estrutura organizacional e os elementos que a compõem, como as unidades organizacionais, para se chegar ao detalhamento de suas funções, atribuições e atividades, que incidem diretamente na produção dos documentos arquivísticos.

Como foi anteriormente posto, partir do conhecimento do sujeito criador dos arquivos é uma opção teórico-metodológica que incide diretamente sobre o princípio de divisão a ser adotado, ou seja, a função. $E$ isto pode ser claramente verificado na notação utilizada no manual coordenado por Bernardes (2008), qual seja: I - órgão produtor; II função; III - subfunção; IV- atividade; e V- série documental.

As funções, atribuições e atividades estarão representadas nas classes e subclasses do plano de classificação, ou seja, na sua estrutura classificatória. É fundamental que recorramos, mais uma vez, à contribuição da teoria da classificação - advinda da lógica aristotélica e profundamente analisada por Ranganatham, que resultou na Classificação dos Dois Pontos - para esta sistematização/estruturação em classe, característica, gênero, espécie e diferença, entre muitos outros princípios.

De maneira muito sucinta, podemos assim explicar alguns desses princípios. Classe: conjunto de coisas ou ideias que possuem um ou vários atributos, predicados ou qualidades em comum. Característica: qualidade ou atributo escolhido para formar as classes. Gênero: conjunto de coisas e ideias que podem ser divididas em dois ou mais grupos de espécies. Espécie: grupo resultante da divisão de um gênero por determinada característica. Diferença: qualidade ou atributo que distingue as espécies, isto é, características diferenciadoras.

Por ser a materialização da existência de uma função e de uma atividade, as tipologias documentais são enfatizadas nos trabalhos de Sousa (2007) e de Bernardes (2008), mas enquanto o primeiro entende que o levantamento das mesmas é uma etapa a ser cumprida na elaboração dos planos de classificação, Bernardes (2008) as utiliza na divisão, tanto que a série documental corresponde ao último dígito da notação adotada.

Fazendo uma analogia com os esquemas de classificação bibliográficos (CDD e CDU), as notações das séries documentais de tipologia documental, propostas por Bernardes (2008), poderiam ser 
pensadas no que encontramos nas tabelas auxiliares de forma documental desses esquemas. Não fazem parte das classes principais dos esquemas (000 a 900), mas suas notações são acrescidas ao final da notação principal, quando extremamente necessárias, e seguindo o princípio da relação.

Não resta dúvida de que os métodos de classificação que não respeitavam a produção e a acumulação originais da documentação e que resultaram, em alguns casos, nas famosas divisões por seções (legislativa; administrativa; dominial; judiciária e histórica) são uma "fortaleza que se rendeu" 20, há um bom tempo, ao princípio de respeito aos fundos. Isto foi possível observar nos autores citados, quando da eleição do conhecimento do sujeito criador dos arquivos como primeiro recorte conceitual a ser dado na elaboração dos planos de classificação para documentos arquivísticos.

O segundo ponto em comum entre os autores tratados foi distinguir as duas categorias de funções desempenhadas pelas instituições, ou seja, atividades-meio e atividades-fim, para daí extraírem, de maneira hierárquica, o princípio de divisão baseado em funções, subfunções e atividades, que corresponderiam, respectivamente, a classes, subclasses e divisões.

O modelo proposto por Sousa (2007), de trabalhar com duas dimensões do criador do arquivo - o seu contexto histórico e a sua individualidade enquanto instituição, possibilita, por um lado, vincular a instituição ao seu contexto político, administrativo e social e, por outro, verticalizar o conhecimento do funcionamento da mesma.

Assim sendo, o autor acrescenta uma etapa importante para a construção dos planos de classificação, que extrapola o âmbito da caracterização da instituição, ao buscar entender o contexto no qual a mesma se insere. Neste ponto, podemos restabelecer um diálogo com a teoria da classificação para a elaboração de um esquema de classificação, pois um dos primeiros passos a ser dado nessa empreitada é mapear o universo do conhecimento, objeto da classificação, para depois se estabelecer o nível de extensão do corte classificatório. Nesse sentido, mapear significa decidir o domínio do conhecimento que servirá de base para a organização das unidades classificatórias. Com a sua preocupação em conhecer o contexto no qual se insere uma dada instituição, Sousa (2007) busca um alargamento dos assuntos tratados nos documentos, além da relação raiz/núcleo (no caso sujeito-produtor), levando-se em conta as formas como as unidades de conhecimento se relacionam, ou seja, o contexto no qual se inserem.

Dessa forma, propomos o acréscimo de duas etapas no modelo elaborado por Sousa (2007, p.149): Fatores a considerar e Validação técnica (RIOS, 2009, p. 95).

\footnotetext{
${ }^{20}$ Expressão usada por Cardoso e Brignoli (1983).
} 
QUADRO 1 Modelo de análise de funções de uma organização

\begin{tabular}{|c|c|}
\hline ETAPAS & ELEMENTOS \\
\hline$\overline{1 \text { 1- Fatores a considerar }}$ & $\begin{array}{ll} & \text { Existência de legislação arquivística e } \\
\text { - } & \text { Princípios que regem a construção de linguagens } \\
& \text { documentárias }\end{array}$ \\
\hline 2- Contextualização & $\begin{array}{l}\text { - Denominação (nome e sigla), localização, área de } \\
\text { atuação, criação e vinculação administrativa e } \\
\text { política }\end{array}$ \\
\hline 3 - Estrutura organizacional & $\begin{array}{l}\text { - Organograma, atribuições, } \\
\text { organizacionais da atividade-meio e da atividade- } \\
\text { fim e alterações e modificações }\end{array}$ \\
\hline 4 - Unidade organizacional & $\begin{array}{l}\text { - Denominação, localização, responsáveis, } \\
\text { vinculação hierárquica }\end{array}$ \\
\hline 5- Atribuição & $\begin{array}{l}\text { - Descrição das atividades que compõem } \\
\text { atribuição }\end{array}$ \\
\hline 6- Atividade & - Descrição das tarefas que compõem a atividade \\
\hline 7 - Tarefa & $\begin{array}{l}\text { - Identificação dos tipos documentais que podem } \\
\text { ser resultado das tarefas executadas. }\end{array}$ \\
\hline 8 - Validação técnica & $\begin{array}{l}\text { - Aplicável para áreas complexas, em termos } \\
\text { técnicos. }\end{array}$ \\
\hline
\end{tabular}

Fonte: Adaptado por RIOS (2009, p.95) de SOUSA (2007, p.149).

Por fim, acentuamos a importância da elaboração e da qualidade de um índice relativo em plano de classificação ou em um esquema de classificação bibliográfica, que deverá incluir todos os assuntos e respectivos sinônimos, com as notações, de modo a facilitar a localização dos assuntos através das notações, nos esquemas de classificação.

\section{Conclusão}

O presente trabalho procurou demonstrar a necessidade de um diálogo entre especialidades, para a sustentação dos princípios teóricos e metodológicos que devem ser levados em conta na construção de planos de classificação para documentos arquivísticos e, considerando, os já existentes princípios e teorias de classificação que visam à organização do conhecimento registrado nos documentos.

$\mathrm{Na}$ literatura arquivística, nacional e internacional, observou-se um consenso sobre a importância da classificação dos documentos na fase corrente dos arquivos. Entretanto, quanto aos princípios teóricos e metodológicos que regem a construção dos planos de classificação de documentos arquivísticos, especialmente no que se refere à escolha de um princípio de divisão, constataram-se controvérsias, que por sua vez, poderiam ser discutidas a partir de um diálogo maior com outras áreas do conhecimento, especialmente a Lógica e a Ciência da Informação.

Destacamos, na pesquisa bibliográfica analisada no âmbito nacional sobre o tema, o trabalho de Sousa (2007), resultado de seu 
doutoramento, quando fez uma pesquisa exaustiva sobre os princípios teóricos e metodológicos que regem a construção dos planos de classificação e apresentou um modelo de análise que trabalha com duas dimensões do sujeito criador do arquivo: seu contexto e a sua individualidade. Se existe um consenso na área, ele se resume a ter como primeiro corte conceitual, para montagem do plano, o conhecimento da instituição, baseado no princípio de respeito aos fundos. A partir disso observa-se, salvo alguma exceção, a nossa produção acadêmica escassa sobre o tema e apresentando controvérsias quanto ao princípio de divisão.

Parece-nos que a manutenção da tradição "manualística" ainda é uma marca da área da Arquivologia, que busca por soluções práticas para os problemas com relação à organização da informação. Daí seja uma das várias explicações que justificam a sua inserção no âmbito das classificações pragmáticas que está apontada na literatura pesquisada.

Por fim, acreditamos que por meio da teoria da classificação denominada "bibliográfica" $\mathrm{e}$, em especial, com o auxílio dos fundamentos de um modelo baseado na lógica analítico-sintético (facetada), é possível compreender as ações do homem e as manifestações do conhecimento humano registrados nas diversas espécies de documentos, inclusive os de natureza arquivística, de modo a organizar e a sistematizar o conhecimento, as idéias, as coisas, as ações, assim como estruturar domínios do conhecimento, suas filiações e conexões que são imperativos para a organização dos documentos nas unidades e nos serviços de informação como os arquivos.

\section{Agradecimentos}

A primeira autora agradece todo apoio recebido da Agência Nacional de Petróleo, Gás Natural e Biocombustíveis, através do seu Programa de Aperfeiçoamento de Recursos Humanos e de toda a equipe da Diretoria Geral, área a qual é subordinada.

\section{Referências}

ARQUIVO NACIONAL (Brasil). Conselho Nacional de Arquivos. Dicionário brasileiro de terminologia arquivística. Rio de Janeiro: CONARQ, 2005.

BARBOSA, A. P. Teoria e prática dos sistemas de classificação bibliográfica. Rio de Janeiro: IBBD, 1969.

BELLOTTO, H. L. Arquivos permanentes: tratamento documental. 3. ed. Rio de Janeiro: FGV, 2005.

BERNARDES, I. P. (Coord.). Manual de elaboração de planos de classificação e tabelas de temporalidade de documentos da administração pública do Estado de São Paulo: atividades-fim. São Paulo: Arquivo Público do Estado de São Paulo, 2008.

BRASCHER, M.; CAFÉ, L. Organização da informação ou organização do conhecimento. In: ENANCIB, 9., 2008, São Paulo. Anais ... São Paulo: 
USP, Programa de Pós-graduação em Ciência da Informação, ANCIB, 2008.

CAMARGO, A. M. A.; BELLOTTO, H. L. (Coords.). Dicionário de terminologia arquivística. São Paulo: AAB, 1996.

CARDOSO, C. F. S.; BRIGNOLI, H. P. Os métodos da história: introdução aos problemas, métodos e técnicas da história demográfica, econômica e social. 3.ed. Rio de Janeiro: Graal, 1983.

CONSELHO INTERNACIONAL DE ARQUIVOS. ISDF: norma internacional para descrição de funções. Rio de Janeiro: Arquivo Nacional, 2008.

DUCHEIN, Michel. O respeito aos fundos em Arquivística: princípios teóricos e problemas práticos. Arquivo \& Administração. Rio de Janeiro, v. 10-14, n. 1, p. 1433, abr. 1982/ago. 1986.

FRENIÈRE, A. Coup d'oeil sur quelques méthodes de classement en gestion des documents. Archives, v. 74, n. 1, p. 20-30, 1974.

RENAUD, J. Le traitement et la conservation des documents. Archives, v. 75, n. 1, p. 13-23, 1975.

GARON, R . Le principe de provenance. Archives, v. 69, n. 2, p. 12-19, 1969 apud HÉON, G. Les plans de classification en archivistique. Archives, v. 27, n. 1, p. 73-90, 1995.

GARON, L. Les fonds d'archives: objet premier de la normalisation en archivistique. In La normalisation en archivistique: un pas de plus dans l'évolution d'une discipline: mélanges Jacques-Ducharme, sous la direction de Carol Couture. Québec: Documentor. Association des archivistes du Québec, p. 105-125, 1992 apud HÉON, G. Les plans de classification en archivistique. Archives, v. 27, n. 1, p. 73-90, 1995.

FOSKETT, A. C. A abordagem temática da informação. São Paulo; Polígono: Brasília, UNB, 1973.

HÉON, G. Les plans de classification en archivistique. Archives, v. 27, n. 1, p. 73-90, 1995.

HJORLAND, B. The concept of "subject" in information science. Journal of Documentation, v. 48, n. 2, p.172-200, 1992.

LARA, M. L. G. Linguagem documentária e terminologia. Transinformação, Campinas, v. 16, n. 3, p. 231-240, set./dez. 2004.

OLIVEIRA, M. I. Classificação e avaliação de documentos: normalização dos procedimentos técnicos de gestão de documentos. Acervo, Rio de Janeiro, v. 20, n. 1-2, p. 133-148, jan./dez. 2007.

PIEDADE, M. A. R. Introdução à teoria da classificação. 2. ed. rev. e aum. Rio de Janeiro: Interciência, 1983.

POMBO, O. Da classificação dos seres à classificação dos saberes. Leituras: Revista da Biblioteca Nacional. Lisboa, n. 2, p. 19-33, primavera, 1998. 
$<$ http://www.educ.fc.ul.pt/docentes/opombo/investigacao/classificacao.pd f> Acesso em: 13 jan. 2009.

PORTAIL INTERNATIONAL ARCHIVISTIQUE FRANCOPHONE. Disponível em: <http://www.piaf-archives.org/>. Acesso em: 27 jul. 2009.

Gestion et traitement : module 04 - gestion des documents actifs: traitement des archives courantes, 2008. Disponível em: $<$ http://www.piaf-archives.org/sections/volet se former/formation>. Acesso em: 27 jul. 2009.

RANGANATHAN, S. R. Prolegomena to library classification. 3.ed. Bombay: Asia Publishing House, 1967.

RIBEIRO, Cândida Fernanda Antunes. Acesso à informação nos arquivos. 1998. Tese (Doutorado em Arquivística) - Faculdade de Letras, Porto, 1998.

RIOS, E. R. Princípios teóricos e metodológicos para construção de planos de classificação documental: um estudo de caso: A Agência Nacional do Petróleo, Gás Natural e Biocombustíveis. 2009. Monografia (Especialização em Organização, Planejamento e Direção de Arquivos) Universidade Federal Fluminense; Arquivo Nacional, Niterói; Rio de Janeiro, 2009.

ROBERGE, M. La classification universelle des documents administratifs. La Pocatière: Documentor, 1985.

SOUSA, R. T. B. A Classificação como função matricial do que fazer arquivístico. In: SANTOS, $\mathrm{V}$. B. (Org.). Arquivística: temas contemporâneos: classificação, preservação digital, gestão do conhecimento. Brasília : SENAC, 2007. p. 115-163.

Classificação em arquivística: trajetória e apropriação de um conceito. 2004. Tese (Doutorado em História Social) - Faculdade de Filosofia, Letras e Ciências Humanas, Departamento de História, Universidade de São Paulo, São Paulo, 2004.

UNIVERSITÉ LAVAL. Gestion des documents administratifs. Disponível em: $<$ http://www.archives.ulaval.ca/gestion des documents administratifs/tr aitement des documentsbractifs/manuel de classification et de classe ment des documents administratifs/> . Acesso em: 27 jul. 2009.

VICKERY, B. C. Classificação e indexação nas ciências. Rio de Janeiro: BNG/Brasilart, 1980.

\section{Bibliografia}

ARAÚJO, C. A. A. Fundamentos teóricos da classificação. Encontros Bibli: Revista Eletrônica de Biblioteconomia e Ciência da Informação, Florianópolis, v. 11, n. 22, p. 117-140, 2006.

ARQUIVO NACIONAL (Brasil). Conselho Nacional de Arquivos. Classificação, temporalidade e destinação de documentos de arquivo 
relativos às atividades-meio da administração pública. Rio de Janeiro: Arquivo Nacional, 2001.

CAMPOS, M. L. A. Linguagem documentária: teorias que fundamentam sua elaboração. Niterói: Eduff, 2001.

CAMPOS, M. L. A.; GOMES, H. E. Organização de domínios do conhecimento e os princípios ranganathianos. Perspectivas em Ciência da Informação, Belo Horizonte, v. 8, n. 2, p. 150-163, jul./dez. 2003.

GONÇALVES, J. Como classificar e ordenar documentos de arquivo. São Paulo: Arquivo do Estado, 1998.

INDOLFO, A. C. O uso de normas arquivísticas no Estado Brasileiro: uma análise do Poder Executivo Federal, 2008. 237 f. Dissertação (Mestrado em Ciência da Informação) - Convênio Universidade Federal Fluminense e Instituto Brasileiro de Informação em Ciência e Tecnologia, Niterói; Rio de Janeiro, 2008.

LANDRIDGE, D. Classificação: abordagem para estudantes de biblioteconomia. Rio de Janeiro: Interciência, 2006.

LIMA, V. M. A. Da classificação do conhecimento científico aos sistemas de recuperação de informação: enunciação de codificação e enunciação de decodificação da informação documentária. 2004. 156 f. Tese. (Doutorado em Ciências da Comunicação - Área de concentração: Ciência da Informação e da Documentação) - Escola de Comunicação e Artes, Universidade de São Paulo, São Paulo, 2004.

RODRIGUES, G. M.; LOPES, I. L. (Orgs.). Organização e representação do conhecimento na perspectiva da Ciência da Informação. Brasília: Thesaurus, 2003. 